Thorax, 1980, 35, 925-928

\title{
Inhaling habits among smokers of different types of cigarette
}

\author{
NICHOLAS J WALD, MARIANNE IDLE, JILLIAN BOREHAM, AND ALAN BAILEY \\ From the ICRF Cancer Epidemiology and Clinical Trials Unit, Radcliffe Infirmary, Oxford, \\ and BUPA Medical Centre, London
}

\begin{abstract}
Inhaling habits were studied in 1316 men who freely smoked their usual brands of cigarette. An index of inhaling was calculated for each person by dividing the estimated increase in carboxyhaemoglobin level from a standard number of cigarettes by the carbon monoxide yield of the cigarette smoked. Smokers of ventilated filter cigarettes inhaled $82 \%$ more than smokers of plain cigarettes $(p<0.001)$ and those who smoked unventilated filter cigarettes inhaled $36 \%$ more ( $>00.001$ ). Cigarette consumption was similar among smokers of each type of cigarette. Assuming that the intake of tar and nicotine is proportional to the inhaling index, the intake in either group of filter cigarette smokers would have been less than that in plain cigarette smokers. Among smokers of unventilated cigarettes, however, the intake would not have been much less.
\end{abstract}

Filter cigarettes, especially those with ventilated filters (which have perforations in the filter through which air can enter and reduce the concentration of the cigarette smoke), deliver less tar and nicotine than plain cigarettes. They are considered less harmful to health, particularly as far as the risk of lung cancer is concerned. However, since filter cigarettes are less "strong" than plain ones, people smoking them may inhale to a greater extent or smoke more of them. A previous study ${ }^{1}$ suggested that smokers of ventilated filter cigarettes did inhale to a greater extent than other cigarette smokers, but this was not quantified and the study drew no firm conclusions regarding the inhaling habits of smokers of unventilated filter cigarettes, the type most commonly smoked. We aimed to examine inhaling in more detail in the present study, and for simplicity used the term inhaling in a broad sense to refer to the intake of tobacco smoke from a cigarette including contributions from the number of puffs, puff volume, and the depth to which smoke is inspired into the lungs.

\section{Methods}

The study population consisted of men aged 35 to 64 years (mean $47 \mathrm{yr}$ ) who attended the BUPA Medical Centre in London for a comprehensive

Address for reprint requests: Dr NJ Wald, ICRF Cancer Epidemiology and Clinical Trials Unit, Radcliffe Infirmary, Oxford OX2 6HE. health screening examination. The men were asked about their medical history and their usual and recent smoking habits. All information was collected after arrival at the Medical Centre, and the men were not forewarned about the survey of smoking habits. The time when each cigarette, cigar or pipe was smoked since waking that day was recorded, together with the manufacturer's brand. Each man provided a sample of venous blood and the carboxyhaemoglobin $(\mathrm{COHb})$ saturation was measured as previously described. ${ }^{2}$ The within-assay standard deviation of the method was $0.05 \% \mathrm{COHb}$. Tar and nicotine yields of the cigarettes smoked were obtained from tables published by the Health Departments of the United Kingdom, and carbon monoxide (CO) yields were obtained from the Tobacco Advisory Council. Both the tar/nicotine and the CO yields were determined under the same standard conditions.

Our statistical analysis considers men seen between early 1975 and September 1977, who usually smoked only manufactured cigarettes. Men who smoked brands of cigarettes for which $\mathrm{CO}$ yields were not available from the Tobacco Advisory Council (54) were excluded. The analysis was restricted to the 1316 men who smoked between one and 16 cigarettes before the blood test on the day they were seen at the Medical Centre, since only a few men smoked any given number of cigarettes greater than 16. 


\section{Results}

The table shows that the mean number of cigarettes usually smoked each day was similar for smokers of plain, ventilated filter, and unventilated filter cigarettes. The mean $\mathrm{COHb}$ levels were, however, significantly different, and these differences persisted after the $\mathrm{COHb}$ levels were indirectly standardised for the number of cigarettes smoked before the test to take account of any differences between smokers of the three types of cigarette, using all the smokers as the standard population. For smokers of ventilated and unventilated filter cigarettes the standardised $\mathrm{COHb}$ levels were, respectively, $23 \%$ and $35 \%$ higher than that for smokers of plain cigarettes $(p<0.001)$.

Table Mean cigarette consumption, $\mathrm{COHb}, \mathrm{CO}$ y:elds, and inhaling index according to type of cigarette (standardised values were indirectly standardised for number of cigarettes smoked before test)

\begin{tabular}{|c|c|c|c|}
\hline & \multicolumn{3}{|c|}{ Type of cigarette smoked } \\
\hline & Plain & $\begin{array}{l}\text { Ventilated } \\
\text { filter }\end{array}$ & $\begin{array}{l}\text { Unventila- } \\
\text { ted filter }\end{array}$ \\
\hline Number of men & 110 & 331 & 875 \\
\hline $\begin{array}{l}\text { Cigarette consumption: } \\
\text { Number per day }( \pm \text { SD) } \\
\text { Number before test }( \pm \text { SD) }\end{array}$ & $\begin{array}{r}23 \cdot 8 \pm 9 \cdot 3 \\
7 \cdot 3 \pm 3 \cdot 5\end{array}$ & $\begin{array}{r}24 \cdot 2 \pm 10 \cdot 2 \\
7 \cdot 4 \pm 3 \cdot 6\end{array}$ & $\begin{aligned} 23 \cdot 7 & \pm 10 \cdot 2 \\
7 \cdot 1 & \pm 3 \cdot 8\end{aligned}$ \\
\hline $\begin{array}{l}\text { COHb (\%): } \\
\text { Unstandardised* }( \pm \text { SD) } \\
\text { Standardised }{ }^{*} \\
\text { Standardised excess above } \\
\text { background and carryover* }\end{array}$ & $\begin{array}{l}4 \cdot 1 \pm 1 \cdot 5 \\
4 \cdot 0 \\
2 \cdot 2\end{array}$ & $\begin{array}{l}5 \cdot 0 \pm 2 \cdot 0 \\
4 \cdot 9 \\
3 \cdot 1\end{array}$ & $\begin{array}{l}5 \cdot 4 \pm 2 \cdot 3 \\
5 \cdot 4 \\
3 \cdot 6\end{array}$ \\
\hline $\begin{array}{l}\text { CO yields: } \\
\text { (mg!cigarette smoked) } \\
\text { Standardised COHb inhaling } \\
\text { index }{ }^{*}(\mathrm{COHb} \% / \mathrm{mg} \mathrm{CO})\end{array}$ & $\begin{array}{c}15 \cdot 6 \pm 1 \cdot 7 \\
0 \cdot 143\end{array}$ & $\begin{array}{c}12.2 \pm 1.9 \\
0.260\end{array}$ & $\begin{array}{c}18 \cdot 9 \pm 2 \cdot 5 \\
0 \cdot 194\end{array}$ \\
\hline
\end{tabular}

${ }^{*} \mathrm{p}<0.001$ (randomisation test) for (1) each type of filter versus plain and (2) ventilated versus unventilated.

$\mathrm{COHb}$ levels include a contribution from the $\mathrm{COHb}$ carryover from the previous day's smoking and the background $\mathrm{COHb}$ from endogenous $\mathrm{CO}$ and atmospheric CO. For each person this contribution was taken as the $\mathrm{COHb}$ level among men who did not smoke on the day of the test but who smoked a similar number of cigarettes during the previous evening. It was $0.9 \%, 1.2 \%, 1.4 \%, 1 \cdot 7 \%$, and $2 \cdot 1 \%$ respectively for those who smoked no, one to three, four to six, seven to nine or more than nine cigarettes after 1600 hours the day before. The table shows the mean $\mathrm{COHb}$ levels minus this contribution ("excess" $\mathrm{COHb}$ ). Among smokers of ventilated and unventilated filter cigarettes the excess $\mathrm{COHb}$ levels were, respectively, $41 \%$ and $64 \%$ greater than among smokers of plain cigarettes, whereas the $\mathrm{CO}$ yields of the cigarettes (see table) were, respectively, 22\% lower and $21 \%$ higher, indicating that both types of filter cigarette were inhaled to a greater extent than plain cigarettes.

A quantitative index of inhaling by an indi- in vidual smoker, which takes account of both the background and carryover $\mathrm{COHb}$ as well as the $\mathrm{CO}$ yield of the particular cigarette smoked, is $\vec{\omega}$ given by the excess $\mathrm{COHb}$ level divided by the $\mathrm{CO}$ \% yield of the cigarette. Since this index depends on $\vec{x}$ the number of cigarettes smoked before the $\mathrm{COHb}$ test, the mean $\mathrm{COHb}$ inhaling index for $\vec{N}$ each group of smokers was indirectly standardised for the number of cigarettes smoked, and we $\mathcal{N}$ called this the standardised $\mathrm{COHb}$ inhaling index. 음 For the smokers of ventilated filter cigarettes this index was $82 \%$ more than for the smokers of plain cigarettes $(p<0.001)$, and for smokers of un- $\overbrace{\overparen{D}}^{\infty}$ ventilated filter cigarettes it was $36 \%$ more $(\mathrm{p}<0.001)$ (see table).

The figure shows the estimated actual intake of tar and nicotine per cigarette for the filter cigarette smokers relative to plain, taking into. account the differences in inhaling. If the filter cigarettes were inhaled to the same extent as the plain ones, the expected relative intake of tar or nicotine (shown in the figure by the dotted lines) would simply be the ratio of the tar or nicotine $\Omega$ yields. The actual relative intake was estimated by $\overline{\bar{a}}$ multiplying the expected intake by the standard- $\exists$ ised inhaling index expressed as a percentage of that for plain cigarette smokers. For both types of filter cigarette the estimated intake of tar and nicotine was much greater than the expected $\frac{0}{0}$ values. In neither case was the intake as great as $x$ that for plain cigarettes, but for smokers of unventilated filter cigarettes it was not much less.

\section{Discussion}

Men who smoked filter cigarettes inhaled sub- $\frac{D}{0}$ stantially more than smokers of plain cigarettes although their cigarette consumption was similar. 요 As a result any benefit to health associated with $N$ smoking filter cigarettes, rather than plain ones, N is likely to be less than expected on the basis of $\mathscr{\sigma}$ their relative tar yields. A number of studies have suggested that smokers of low tar cigarettes have $\stackrel{0}{\odot}$ a lower risk of lung cancer than smokers of high tar cigarettes, ${ }^{34}$ and in the UK, associated with $a_{0}^{+}$ change to filter cigarettes, there has been a de-o crease in lung cancer mortality among men aged $\overrightarrow{\mathbb{D}}$ less than 60 years. $^{5}$ The results of our present $\frac{?}{\Phi}$ study suggest that the reduction in tar yield $\frac{\varrho}{\sigma}$ may only partially explain these epidemiological observations. 


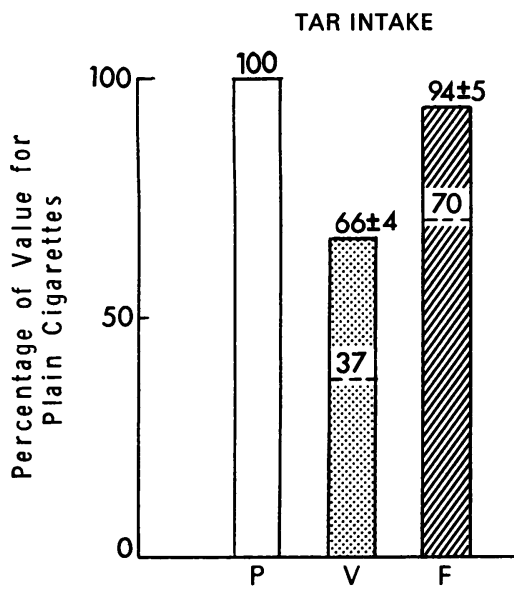

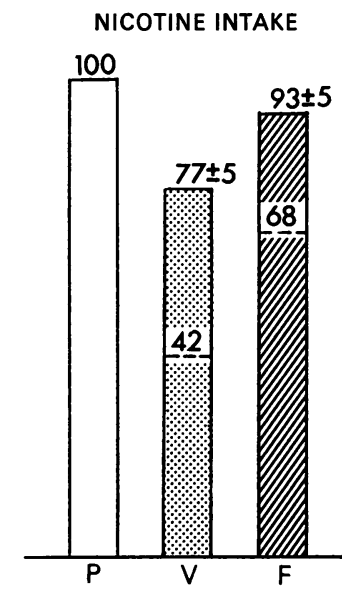

Figure Tar and nicotine intake per cigarette ( \pm standard error) as percent of value for plain cigarettes. The dotted lines indicate the intake of tar and nicotine which would be expected if all three cigarettes were smoked in the same way. $P=$ plain, $V=$ ventilated filter, and $F=$ unventilated filter cigarette. The mean tar yields were $26 \cdot 0,9 \cdot 5$, and $18 \cdot 1 \mathrm{mg} /$ cigarette respectively. The mean nicotine yields were $1 \cdot 9,0 \cdot 8$, and $1.3 \mathrm{mg} /$ cigarette.
Our results relating to unventilated filter cigarettes are the most important because most cigarettes sold are of this type. However, the proportion of the cigarette market occupied by ventilated filter cigarettes has recently been increasing. In 1974 the market share of plain, ventilated, and unventilated filter cigarettes in the UK was about $15 \%, 6 \%$, and $79 \%$ respectively. In 1978 the figures were $10 \%, 15 \%$, and $75 \%$ (WS Paige, personal communication).

Our results relating to ventilated cigarettes may have been caused partly by smokers blocking the perforations in the filter, say with their fingers or lips, as has sometimes been found to occur (LT were not influenced by any such bias.

The results of this study are likely to be generally applicable for two reasons. Firstly, they relate to men who smoked their usual brands of cigarette as they wished without being aware of the investigation until they attended the Medical Centre. Secondly, the men who had changed from plain to filter cigarettes had done so many years before, $98 \%$ having switched at least two years previously. One other long-term study yielded qualitatively similar results to our own ${ }^{6}$ and one did not, though in the latter the change in tar yield was not great. ${ }^{7}$ Most other studies, usually laboratory-based, have been mainly concerned with the short-term effects of switching from high-tar to low-tar cigarettes or vice versa. In general, it was concluded that switching altered inhaling habits, ${ }^{8-13}$ though where the change in tar yield was not great, no material alteration in inhaling habits was again noted. ${ }^{14}$ In our own study the type of cigarette was the principal determinant of smoking behaviour, while switching itself was less important; smokers who had switched from plain to ventilated filter and unventilated filter cigarettes inhaled $2 \%$ and $6 \%$ more, respectively, than those who had always smoked filter cigarettes, and these differences were not statistically significant. Switching from plain to filter cigarettes was also not associated with any material change in daily cigarette consumption.

The estimation of the actual intake of tar and nicotine shown in the figure rests on two assumptions. The first is that the $\mathrm{COHb}$ inhaling index is directly proportional to the extent of intake of $\mathrm{CO}$ from tobacco smoke. This is likely to be approximately correct since the alveolar concentration of $\mathrm{CO}$ is likely to be proportional to the extent of inhaling, and we have confirmed that the relationship between end-tidal $\mathrm{CO}$ concentration and $\mathrm{COHb}$ appears approximately linear. Secondly, it assumes that the proportions of the different constituents of tobacco smoke inhaled remain constant, so that, for example, one smoker whose inhaling index is twice that of another smoking the same brand of cigarette inhales, on average, twice as much tar as the other smoker, and this is likely to be approximately true. It does not, however, necessarily follow that the deposition of $\operatorname{tar}$ on the bronchial mucosa is also double. If it is less, this might explain why the risk of lung cancer associated with smoking filter cigarettes is less than our data would suggest.

There are data to support our assumption that nicotine delivery to the lungs is approximately proportional to the $\mathrm{CO}$ intake. For example, it has been shown that $\mathrm{COHb}$ levels are closely associated with plasma nicotine levels in subjects who smoked cigarettes using different dilution filters. ${ }^{14}$ Tar delivery is also likely to be related to $\mathrm{CO}$ intake since nicotine and tar are both in the par- 
ticulate phase of cigarette smoke and are, therefore, likely to be delivered to the lungs in a similar way.

$\mathrm{COHb}$ levels in smokers can be affected by several factors other than those considered in our analysis, such as the time of day when blood for the $\mathrm{COHb}$ test was taken, and these might have led to bias if associated with the type of cigarette smoked. We examined these factors as in previous studies, ${ }^{12}$ and again concluded that our results were not influenced by any such bias.

Our data provide no indication of which constituent of tobacco smoke may have influenced the extent of inhaling. Although inhaling was considered in relation to the tar and nicotine yield of the cigarettes smoked neither need be responsible for the differences in inhaling which were observed.

We thank Sir Richard Doll, Dr HS Cuckle, and Mr PN Lee for their comments, Mr R Peto for statistical advice, the Tobacco Advisory Council for providing the $\mathrm{CO}$ yields of different brands of cigarette, and the Medical Research Council for part of our financial support.

\section{References}

1 Wald N, Idle M, Smith PG, Bailey A. Carboxyhaemoglobin levels in smokers of filter and plain cigarettes. Lancet 1977; 1:110-2.

2 Wald N, Idle M, Bailey A. Carboxyhaemoglobin levels and inhaling habits in cigarette smokers. Thorax 1978; 33:201-6.

3 Wynder EL, Mabuchi K, Beattie EJ. The epidemiology of lung cancer. Recent trends. JAMA 1970; 213:2221-8.

4 Hammond EC, Garfinkel L, Seidman H, Lew EA. "Tar" and nicotine content of cigarette smoke in relation to death rates. Environ Res 1976; 12: 263-74.

5 Wald NJ. Mortality from lung cancer and coronary heart disease in relation to changes in smoking habits. Lancet 1976; 1:136-8.

6 Russell MAH, Jarvis M, Iyer R, Feyerabend C. Relation of nicotine yield of cigarettes to blood nicotine concentrations in smokers. $\mathrm{Br}$ Med J 1980; 1:972-98.

7 Freedman S, Fletcher CM. Changes of smoking habits and cough in men smoking cigarettes with 30\% NSM tobacco substitute. Br Med J 1976; 1: 1427-30.

8 Ashton H, Watson DW. Puffing frequency and nicotine intake in cigarette smokers. $\mathrm{Br}$ Med J 1970 ; 3:679-81.

9 Frith CD. The effect of varying the nicotine content of cigarettes on human smoking behaviour. Psychopharmocology 1971; 19:188-92.

10 Russell MAH, Wilson C, Patel UA, Cole PV,
Feyerabend C. Comparison of effect on tobacco consumption and carbon monoxide absorption of $\frac{\bar{c}}{7}$ changing to high and low nicotine cigarettes. $B r \stackrel{\Phi}{\varnothing}$ Med J 1973; 4:512-6.

11 Turner JAMcM, Sillet RW, Ball KP. Some ${ }^{\mathscr{D}}$ effects of changing to low-tar and low-nicotine $\vec{O}$ cigarettes. Lancet 1974; 2:737-9.

12 Russell MAH, Wilson C, Patel UA, Feyerabend $\vec{\omega}$ C, Cole PV. Plasma nicotine levels after smoking? cigarettes with high, medium and low nicotine $x$ yields. Br Med J 1975; 2:414-6.

13 Ashton H, Stepney R, Thompson JW. Self- titration by cigarette smokers. Br Med J 1979; 2:357-60.

14 Sutton SR, Feyerabend C, Cole PV, Russell ${ }^{\text {O }}$ MAH. Adjustment of smokers to dilution of 3 tobacco smoke by ventilated cigarette holders. Clin Pharmacol Therap 1978; 24:395-405.

\section{Statistical appendix}

RANDOMISATION TEST OF STATISTICAL SIGNIFICANCE

Differences in the mean value of a variable $x$ (either $x=\varnothing$ $\mathrm{COHb}$, or, in other analyses, $\mathrm{x}=$ inhaling index) measured on men smoking two types of cigarette (A and B) were tested for statistical significance within 16 strata defined by the number of cigarettes smoked before the test. (Nobody in the study had smoked more than 16 cigarettes before the test.)

The underlying idea is to compare like with like, and to avoid comparing, for example, people who have smoked $\overline{0}$ only five cigarettes with people who have already smoked 10 before the test.

In a particular stratum $\mathrm{i}$ :

Let $N_{i}$ be the total number of men smoking i cigarettes before the test, and let $n_{i}$ be the number smoking type $A$ only.

Define $o_{i}$ to be the sum of the $n_{i}$ observed values of $x \frac{\dot{\sigma}}{3}$ for men smoking type $A$.

Define $\bar{x}_{i}$ to be the overall mean value of $x$ in stratum iô and $S_{i}{ }^{2}$ to be the variance estimator derived from the $\mathrm{x}$-values in stratum $\mathrm{i}$ by

$$
\mathrm{Si}_{\mathrm{i}}{ }^{2}=\Sigma\left(\mathrm{x}-\overline{\mathrm{x}}_{\mathrm{i}}\right)^{2} /\left(\mathrm{N}_{\mathrm{i}}-1\right) \text {. }
$$

If the $n_{i}$ men smoking type $A$ were chosen at random from the total $N_{i}$, then by standard permutational $N$ arguments the expectation of the sum of their $x$-values. would be $e_{i}$ and its variance $v_{i}$, where $e_{i}=n_{1} \bar{x}_{1}$ and $N$ $\mathbf{v}_{\mathbf{i}}=\mathbf{n}_{\mathbf{i}}\left(\mathbf{l}-\mathbf{n}_{\mathrm{i}} / \mathbf{N}_{\mathbf{i}}\right) \mathbf{S}_{\mathbf{i}}{ }^{2}$.

Summing $o_{i}, e_{i}$ and $v_{i}$ over all 16 strata gives:

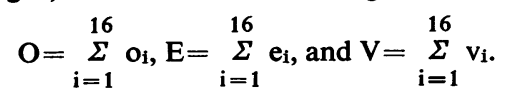

If $A$ smokers differ from $B$ smokers with respect to variable $x$, given the number of cigarettes smoked before the test, $\overrightarrow{0}$ then $O$ should be systematically different from $E$. To test $\mathbb{\Phi}^{\circ}$ whether this is so, we note that if there were no difference $\frac{?}{\mathbb{D}}$ between A smokers and B smokers, then $O$ would differ 2 only randomly from $E$, so that $(O-E)$ would have expectation zero and variance $\mathrm{V}$, and $(\mathrm{O}-\mathrm{E})^{2} / \mathrm{V}$ would be distributed approximately as $\chi_{1}{ }^{2}$. 